\title{
Coro dos Maus Alunos - notas de um processo de montagem
}

\section{Coro dos Maus Alunos - notes from a theatre creative process}

Heloise Baurich Vidor ${ }^{1}$

Barbara Biscaro ${ }^{2}$ 


\section{Resumo}

Este texto traz as impressões do processo de montagem e apresentações do espetáculo teatral Coro dos Maus Alunos, do dramaturgo português Tiago Rodrigues, pela perspectiva das professoras da disciplina e diretoras da obra. O espetáculo foi criado no contexto da disciplina Montagem Teatral I e II, do curso de Licenciatura em Teatro da Universidade do Estado de Santa Catarina (UDESC). A escola dentro da escola, a presença da Arte na escola, o binômio professor-artista, o coro como lugar da coletividade são alguns dos temas que, em diálogo com Jorge Larrosa, Jan Masschelein e Maarten Simons, Daniel Pennac, perpassam a reflexão.

Palavras-chave: Juventude; formação docente; pedagogia do teatro; montagem teatral

\section{Abstract}

This text brings the impressions from the teachers and directors of the creative process and posterior performances of the play Coro dos Maus Alunos. The performance was created in the context of the course Montagem Teatral I and II, of the graduation in the already mentioned University, which has the goal of making a production with students conducted by teacher-artists. The school inside the school, the presence of Art in regular school, the teacher-artist binomial, the chorus as the collective, are some of the themes that, in dialogue with the authors Jorge Larrosa, Jan Masschelein and Maarten Simons, Daniel Pennac, enrich the ideas arranged on this text.

Keywords: youth; teacher's formation; Theatre pedagogy; theatre-making

E-ISSN: 2358.6958

\footnotetext{
1 Professora doutora efetiva - Departamento de Artes Cênicas da UDESC e dos programas de Pós-graduação PPGT e PROFARTES - Universidade do Estado de Santa Catarina (UDESC). heloisebvidor@gmail.com

2 Pesquisadora vocal e professora doutora colaboradora da área de Voz no Departamento de Artes Cênicas da Universidade do Estado de Santa Catarina. Atriz e diretora, tem como foco os estudos em vocalidade na cena. barbara.biscaro@gmail.com
} 
Nós nem sempre concordamos já lembramos tudo o que aconteceu muitas vezes e nem sempre concordamos ás vezes mudam as datas outras vezes as frases nem tudo o que vamos contar aconteceu exatamente assim [...]. Tiago Rodrigues

Este texto é escrito a quatro mãos, em um processo de notas e reflexões sobre o percurso da montagem do espetáculo Coro dos Maus Alunos na disciplina de Montagem Teatral 1 e 2 da Licenciatura em Teatro da Universidade do Estado de Santa Catarina, durante o ano de 2018. A escritura deste relato, feita pelas duas professoras ministrantes da disciplina, tem como proposta pontuar elementos do processo que capturaram nossa atenção a partir de diversos temas. A juventude, a escola, a relação professor/a-aluno/a, o ensino do teatro, a vontade de ser artista, o espaço para a voz (do/a professor/a, do/a aluno/a), a formação (de professores/ as, de atores e atrizes, de jovens), a violência, o amor, a filosofia, a amizade. Tudo isso misturado, talvez sem ordem ou coerência aparente, fez parte de um longo processo não somente de feitura de um espetáculo teatral, mas também da construção de pontes entre professoras e alunos e alunas durante um ano de trabalho, em uma reflexão viva sobre o que pode o teatro quando ele entra em fricção com o universo adolescente, com o ambiente da escola e com os sonhos de jovens atores e atrizes (futuros professores/as de teatro) na projeção de uma vida possível dentro do mundo das artes, no contexto em que vivemos hoje no Brasil.

\section{A escola dentro da escola dentro da escola}

\#heloise: Coro dos Maus Alunos é um texto que fala sobre a escola, que fala deste lugar por jovens, são os jovens alunos que contam a história, por jovens que estão em outra escola (os atores e atrizes da peça), que é a Universidade.

\#barbara: o autor do texto é Tiago Rodrigues, escrito em Portugal no ano de 2008. Ao longo de todo o processo sempre me pareceu impressionante a atualidade da discussão que ele propõe e as similaridades com o contexto brasileiro, sendo que parte de um retrato europeu da escola e da juventude. Nunca vou me esquecer de quando a Heloise propôs o texto, ainda no ano de 2017. Nesta ocasião ela reforçou o fato de sermos professoras de uma escola (a Universidade). Pode parecer estúpido, mas foi aí que percebi, pela primeira vez com o devido peso, que eu trabalhava em uma escola. O ser professora passou, nesta travessia, a constituir também meus processos de identidade como artista e mulher.

\#heloise: durante o processo de ensaio desejamos nos aproximar da escola, no intuito de olhar (mais atentamente) para o lugar no qual a ficção seria desenvolvida. Voltar para esse lugar, que para alguns fazia pouco que o haviam deixado e que para outros, era um lugar perdido em uma memória longínqua. Então o plano seria: 
encontrar uma escola parceira, que acolhesse o projeto e que topasse correr o risco de ter uma turma de jovens estudantes de teatro, futuros professores, em processo de criação de um espetáculo. Encontramos uma parceria, através dos professores de teatro Maria Izabel de Carvalho e Muniz Mendes e Marcelo Silva Mendes, a EEM Profa. Maria da Glória Viríssimo de Farias (Biguaçu/SC), que toparam a empreitada. Vale ressaltar que não foi uma aproximação pela via da formação do professor, aos moldes dos estágios curriculares obrigatórios ou através de projetos pedagógicos de iniciação à docência, seria algo, mais aos moldes de uma residência artística. Nossa intenção era, como artistas, passarmos algum tempo junto com os estudantes e os professores, compartilhando o processo de criação, criando cenas aos olhos dos estudantes da escola, revelando o ofício do ator, a urdidura de um espetáculo teatral.

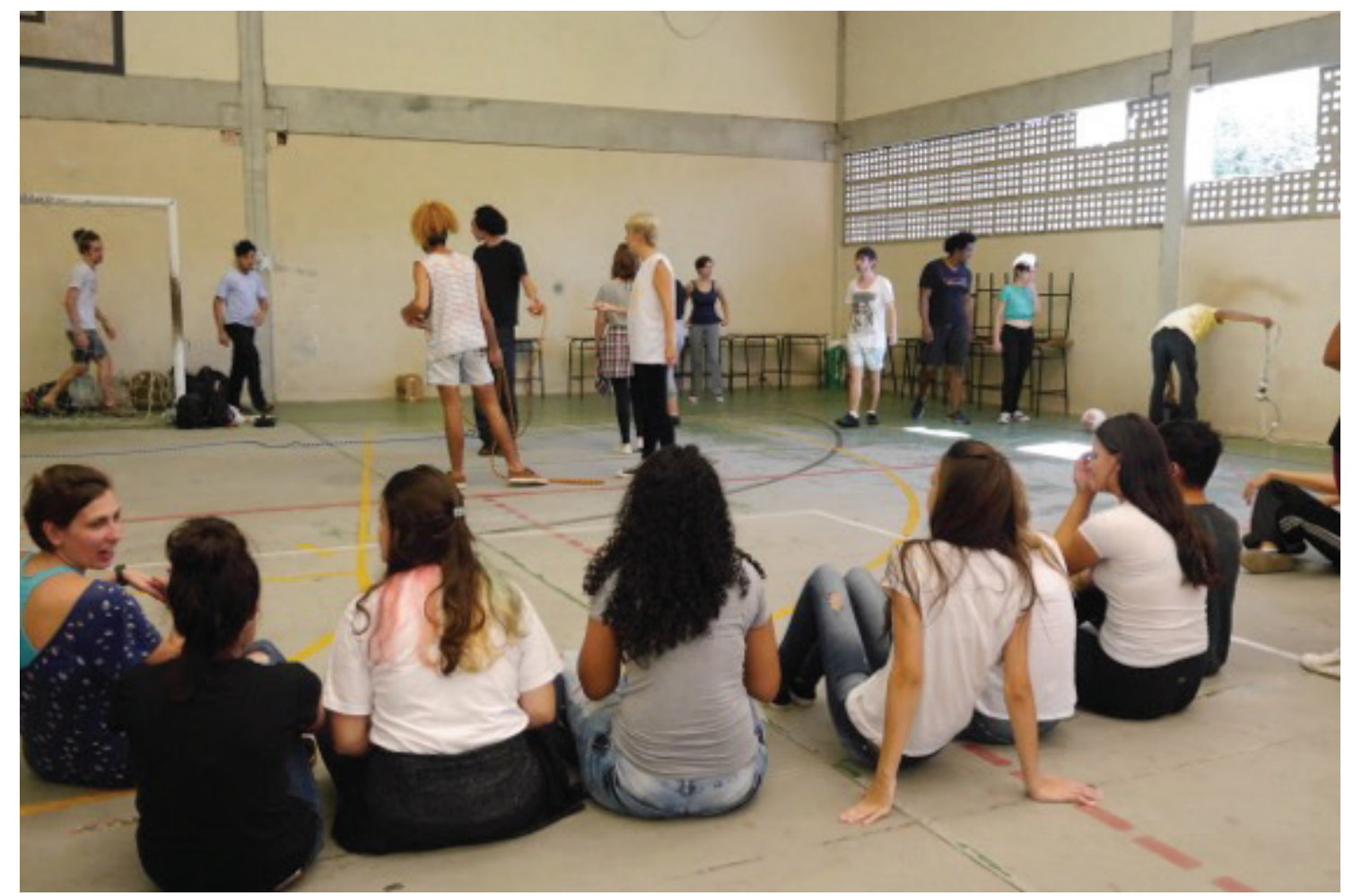

Figura 1 - Ação na escola. Acervo da Montagem. Foto: Mariana Smania (2018).

\#barbara: na montagem usa-se o tempo todo o recurso da metalinguagem, brincando com a sobreposição de diversos universos coexistentes: o universo ficcional da peça, que consiste em jovens alunos/as de uma escola fictícia lembrando-se de um episódio passado que envolve o professor de filosofia; tal ação executada por jovens alunos/as de outra escola real (a Universidade) contando suas impressões e experiências sobre a escola no processo de montagem teatral. Por isso a experiência de intercâmbio com a escola de Biguaçu/SC foi tão importante no processo, porque colocou outra versão de escola, essa mais calcada na realidade, em nosso processo. O diálogo direto com os/as jovens proporcionou uma visão menos idealizada dos temas que estávamos estudando. Ficção e realidade foram sobrepostas em forma de memória, um jogo de espelhos no qual os reflexos existem de modo a constituírem imagens infinitamente multiplicadas. Mesmo que tenhamos partido de um texto teatral e nos proposto a dar 
vida a uma história ficcional, a relação entre arte e vida nunca se perdeu. Talvez por estarmos imersos na prática do ser professora/a: nós as professoras que conduziam um processo, eles/as, os/as aluno/as que pela primeira vez davam aulas de teatro nas disciplinas de Estágio da Licenciatura em Teatro. Talvez por termos tomado consciência, pouco a pouco, que a experiência escolar funda a todos/as nós, impressão essa depois reiterada pelos relatos do público: a escola é um ambiente que todos/as frequentamos, uma das grandes experiências em comum na nossa vida em sociedade.

\#heloise: uma estratégia da relação arte-vida que tem sido explorada por mim há alguns anos é inspirada no modelo de aula-espetáculo, aula-cena, objeto-obra, ou seja, um campo que se situa entre a aula e a cena, que não é aula e que não é cena, no sentido convencional, mas que flerta com essas modalidades. Explorei esses princípios na criação do espetáculo-aula uma lady MACBETH, depois explorei nas leituras compartilhadas com material literário diverso. No caso deste processo com a disciplina de Montagem Teatral, tinha que lidar com o objetivo claro e concreto da disciplina que é efetivamente montar um espetáculo. Então a opção, no Coro dos Maus Alunos, foi escolher um texto que trouxesse o tema da escola, das relações entre professores e alunos, entre professores e diretores, o cotidiano escolar, e, inspirada pela proposta de Brecht com a peça didática, propor através da imersão no processo de criação com esses temas, levar os participantes a refletirem, problematizarem, vivenciarem, todas as nuances que perpassam essas relações nesse lugar.

\#barbara: todas essas camadas constituíram memória fragmentada, caótica, sem ordem de causa ou efeito, sem hierarquias de informações em um percurso de criação teatral. O que é pessoal ou coletivo, o que é interno ou externo, o que é escolar ou social, o que é do/a professor/a ou do/a aluno/a, todas essas polaridades se entremearam, criando um paralelismo no qual cabe, no final, ao espectador juntar as peças do quebra-cabeça. Misturado ao texto teatral na encenação, ficaram, em dado momento, uma série de relatos reais de cada ator e atriz sobre sua própria experiência escolar. Em outro trecho da peça as professoras da disciplina entram em cena, dando ao público um vislumbre da aula de teatro feita na Universidade com seus códigos e dinâmicas específicas. É a escola dentro da escola dentro da escola. 


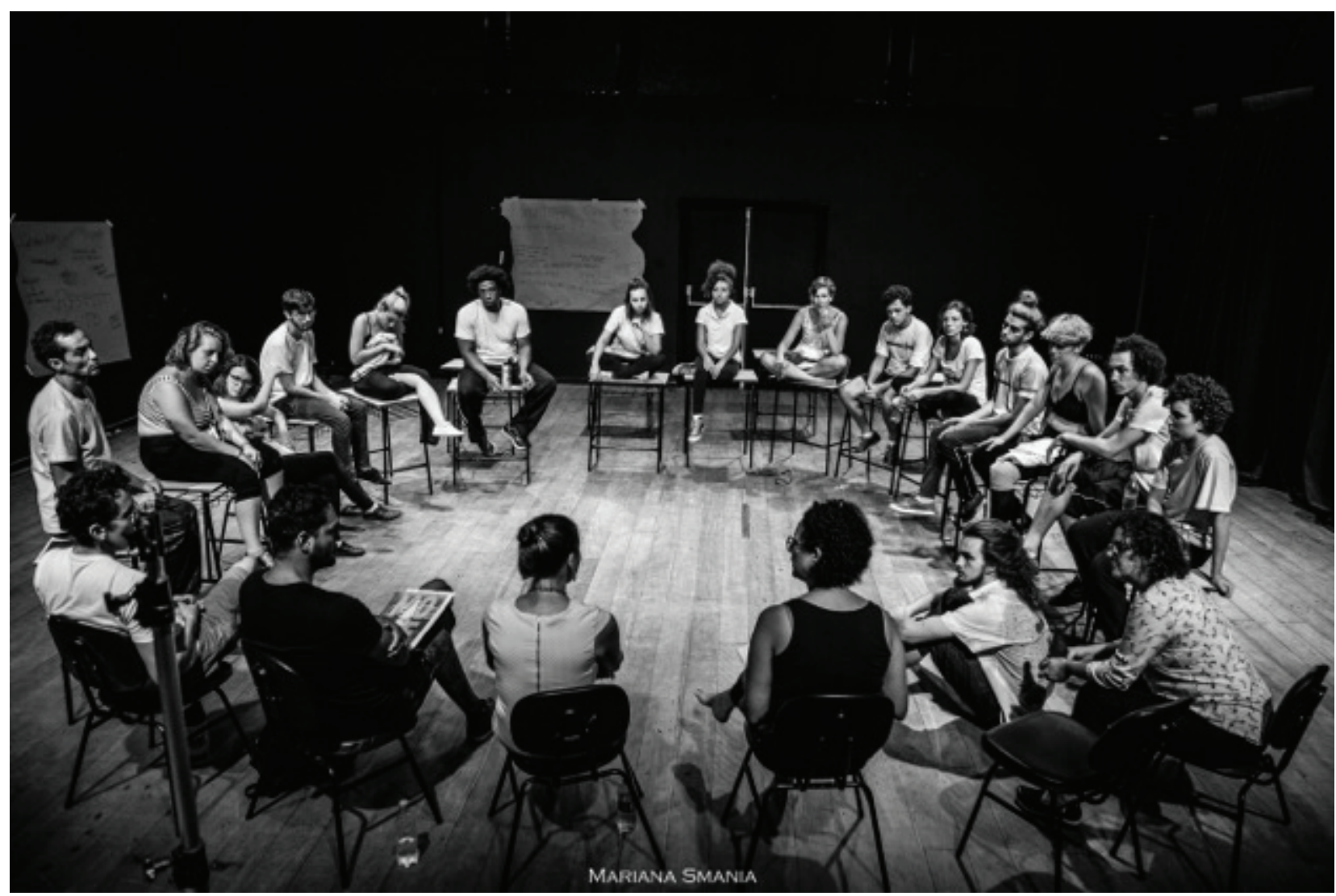

Figura 2 - ensaios abertos com a presença dos professores de teatro da EEM Profa. Maria da Glória Viríssimo de Farias, estagiários docentes e profissionais convidados na discussão com alunos e alunas em sala de ensaio.

Arquivo da Montagem. Foto: Mariana Smania (2018).

\section{Professor/a e artista: binômio impossível?}

\#heloise:éprecisopensarnopapeldo/aprofessor/a, porfuturos/asprofessores/as.Pensar sobre o campo de trabalho com futuros professores/as de teatro através da obra. Isso me lembra do princípio da peça didática de Bertolt Brecht - uma reflexão enquantoseensaiaa obra-aobraéparaqueaquelesqueparticipamdoprocessopossamrefletirsobreoassunto.

\#barbara: durante o processo de montagem, diversas vezes foi reforçada a valorização do percurso e não do produto final. O intuito era que saíssemos tocados pelo processo, tendo vivido um percurso criativo significativo em si. Esse princípio de trabalho, inspirador na teoria, mas difícil de executar na prática, confrontou imagens dos/as alunos/as sobre o que é ser ator e atriz, desafiou minhas próprias imagens do ser professora. Pouco a pouco foram derrubadas idealizações e imagens pueris sobre fama, reconhecimento e sucesso, assim como conseguimos substituir imagens negativas sobre o trabalho "menor" de ser professor/a em confronto com uma imagem supervalorizada ou idealizada do ser artista.

\#heloise: é preciso também pensar sobre o "Mau Aluno". Pensar sobre a escola através da obra artística, aqui no caso, espetáculo teatral. Pensar na obra - espetáculo - como o elemento de mediação entre professores/as e alunos/as, ou seja, a obra é o disparador da conversa entre todos/as sobre a escola, sobre a formação, sobre as relações, etc. 
\#barbara: uma das coisas admiráveis que vimos ocorrer já nas apresentações do trabalho ao público, especialmente quando havia profissionais da educação ou jovens na plateia, é como o acontecimento teatral impele à discussão de elementos que não são possíveis de serem emergidos no dia a dia da escola. $O$ teatro, com suas claras delimitações entre real e fictício, proporcionava um território seguro no qual todos/as podiam se projetar sem comprometer a si. Uma peça que não expõe ninguém, mas ao mesmo tempo fala de tudo e de todos/ as. Neste sentido, o termo didático puxado pela Heloise pode ganhar novos contornos, mais abertos: aprender através da experiência e não da simples retórica (lembrando-se das reflexões da experiência de Jorge Larossa) é uma das potências do teatro? Quais seriam as potenciais identificações desses "maus alunos"?

\#heloise: lembro-me do Pennac, na hora. No livro Diário de Escola (2008), Daniel Pennac, professor e escritor francês, dedica sua escrita a esse que é considerado o Mau Aluno, a ele mesmo, que de Mau Aluno tornou-se um educador e escritor muito conhecido na França (e fora dela também).

Então, eu era um mau aluno. A cada final de tarde de minha infância, eu voltava para casa perseguido pela escola. Meus boletins contavam a reprovação dos meus mestres. Quando não era o último da turma, eu era o penúltimo. (Champagne!) Fechado primeiro para a aritmética e logo em seguida para a matemática, profundamente disortográfico, resistente à memorização e datas e à localização dos lugares geográficos, inapto para a aprendizagem de línguas estrangeiras, com reputação de preguiçoso (lições não aprendidas, trabalhos não feitos), eu levava para casa resultados lamentáveis que não eram compensados com a música nem o esporte. Aliás, com nenhuma atividade paraescolar. -Você entende? Será que ao menos você entende o que eu estou explicando?

Eu não entendia. (Pennac, 2008, p. 15)

Interessa-me o tema do "mau aluno", principalmente no que a fala de Pennac ressaltava a respeito da relação com a música, que podemos ler como teatro, ou arte, e com o esporte. As atividades "paraescolares", que conhecemos como "extra-curriculares" não contavam nada a respeito do potencial deste aluno, que nas disciplinas "escolares" ou "curriculares", eram considerados "maus alunos". Ainda que, aqui no Brasil, desde 1996 a disciplina Arte tenha sido inserida no ensino curricular, o estigma de uma área de conhecimento menor, ou menos importante, ainda a acompanha.

\#barbara: então estamos no território duplamente menor. O menor das artes que habita esse lugar extracurricular na escola e o menor do/a ofício do professor/a que não "deu conta" de ser artista e se dedica à docência? Seria o caso de uma revisão dessa ideia "menor", como na proposta por Deleuze em suas reflexões sobre Kafka?

\#heloise: claro que, no contexto de uma Licenciatura, é inevitável trazer subliminarmente aspectos que flertam com o futuro profissional dos/as estudantes-artistas. Transferir a experiência como alunos de teatro na Universidade para o ambiente da escola é olhar para a escola, querendo ou não. Nesse sentido, o projeto de montagem do espetáculo Coro dos Maus Alunos em um curso de 
Licenciatura em Teatro, em diálogo com professores e alunos de uma escola, foi uma estratégia da professora da área de pedagogia do teatro (eu, no caso) de "viver" efetivamente as questões inerentes à essa área no ambiente escolar.

\#barbara: já eu como professora da área das práticas teatrais, no caso de Voz, entrei no processo pensando muito do ponto de vista da encenação, em como trabalhar com estes estudantes de teatro em um processo artístico. Claro que é necessário pontuar que criar dentro do ambiente da Universidade não é simples. A estrutura institucional escolar (o controle das faltas, a necessidade de avaliação através de notas, a ausência constante dos alunos e alunas, a concomitância com outras disciplinas que exigem de mim e dos estudantes, o cansaço acumulado) proporciona uma espécie de molde que já pré-estabelece as relações. Percebo como foi importante ir tomando consciência das armadilhas que o convívio através da instituição vai proporcionando na relação entre professora-diretora e alunos/as artistas. Uma postura ética foi continuamente reiterada no nosso processo de convivência, pois isso fazia parte tanto quanto um desejo de excelência artística da obra que estávamos produzindo. Um processo humano, que prezasse pela sanidade dos participantes, estava acima de qualquer ambição artística, mesmo que isso nos colocasse novamente nesse lugar "menor", valorizando aspectos que em nossa sociedade não são considerados "produtivos".

\#heloise: lembrando do professor de filosofia (personagem sobre o qual se debruça o texto), outro aspecto que me chama a atenção é a semelhança que esse professor tem com o professor de artes/teatro dentro da escola. Falo aqui daquela acusação (para usar os termos de Masschelein, Simons, Larrosa) de que a matéria de ambos é "inútil". A sensação de que as aulas de filosofia e de artes poderiam perfeitamente serem suprimidas da grade curricular, pois concretamente não servem para nada e ocupam um tempo que poderia ser utilizado com outros "conteúdos mais importantes".

\#barbara: vide uma crescente ideia de produtividade na educação, do aumento dos conteúdos "técnicos" em detrimento daqueles que proporcionam uma formação mais abrangente do que nos constitui seres intrinsecamente sociais.

\#heloise: qual é o professor de artes que nunca sentiu que sua matéria poderia ser simplesmente retirada do currículo e que, a princípio, alguns colegas ou alunos lamentariam, mas que rapidamente isso seria esquecido e engolido pelo fluxo do cotidiano? Acabamos de passar por uma situação de retirada da disciplina Arte do currículo do Ensino Médio na Reforma Curricular que já está em vigor. Houve reação das entidades e instituições envolvidas no tema, e a disciplina foi mantida. Será que a escola realmente quer, suporta, sustenta a arte dentro dela? Será que aquilo que sai do controle é suportado na escola? E aqui, não quero me dirigir à direção ou professores específicos, mas quero trazer à tona o fato de que mesmo o professor que se dispõe a "correr o risco" com uma proposta de ensino libertária, vai enfrentar as reações dos alunos - que não concordam ou se dispõem a um outro jeito de ensinar, de fazer pensar -, vai enfrentar os pais, vai enfrentar os colegas. 
\#barbara: que é exatamente a situação que o professor de filosofia do texto Coro dos Maus Alunos enfrenta. Isso me lembra a fala dele, já no final, quando se dirige aos colegas e pais de alunos e alunas: "reparo que não me acusam de nenhum ato reprovável, mas de promover e incitar comportamentos nos meus alunos que os aqui presentes consideram reprováveis" (Rodrigues, 2008, p. 37). O clima de denúncia e delação que projetos como Escola sem Partido tem proporcionado dialoga diretamente com o texto da peça. O professor de filosofia do texto completa: "dizem que confundi os meus alunos, esquecendo-se que a confusão faz parte da natureza do aluno e é condição da sua idade, é verdade que me aproveito disso, faço-o como qualquer professor deveria fazer porque sem a confusão não se ensina, não se aprende, não se pensa [...]" (Rodrigues, 2008, p. 37). Aceitar a confusão como condição para se aprender a pensar não é tão simples na realidade dos contextos de ensino curricular no Brasil. Nem mesmo dentro da Universidade, local em que diversas vezes a supremacia do "bem-estar" do/a aluno/a castra iniciativas inventivas de professores/as que querem sair de uma determinada zona de conforto.

\#heloise: várias questões implicadas na relação hierárquica que envolve as diversas instâncias da chamada educação são colocadas em xeque e o que fica claro no texto da peça é que, independente do pertencimento ao universo micro ou macro nestas relações, todos os envolvidos se sentem sem voz, sem amparo, às vezes sem esperança. Pelo discurso corrente, os professores de diversas instâncias (ensino fundamental, médio, superior) se sentem perdidos se vendo obrigados a "motivar os alunos", como se com isso pudessem se sentir motivados também. Entretanto, segundo Masschelein e Simons (2014) e também Larrosa (2018), a motivação deveria ser abolida do discurso pedagógico. Sobre isso, tem outra passagem do texto de Masschelein e Simons que esclarece que na escola não se trata de motivar ninguém. O trecho diz: "vamos argumentar que a escola não é sobre o bem-estar, e que falar em termos de (des) motivação é o sintoma infeliz de uma escola enlouquecida, que confunde atenção com terapia e gerar interesse com satisfazer necessidades" (Masschelein; Simons, 2014, p. 17). Esse sintoma infeliz de uma escola enlouquecida surge no texto dramático, quando os alunos contam há alguns anos que houve um escândalo na escola, porque esse professor de filosofia teve um "esgotamento nervoso", um "problema psiquiátrico", e ficou sete anos afastado do ensino. Sobre isso, no final da peça, ele, o professor, diz:

não estou triste com as acusações que me fazem porque com a minha idade já há pouco o que me entristeça e porque aquilo de que me acusam é suficiente para provar como é injusto eu ser aqui acusado como é injusto o boato, o rumor a ignorância que não aceita ficar muda e que tantas vezes discursou sobre mim e me fez até desistir do ensino durante anos mas se alguma coisa aprendi nestes sete anos sem ensinar é que as injustiças não devem nos entristecer ao contrário, devem nos encher com a alegria de as combater por isso voltei a ensinar e daí tirei muito prazer estou alegre portanto. (Rodrigues, 2008, p. 34-35) 


\section{O coro como o lugar da coletividade}

\#heloise: outra palavra instigante, que aparece no título do texto é "coro". Seja a palavra grega Khóros ou a latina Chõrus, coro nos remete aos primórdios do teatro, onde na Grécia, no século VI a. C., já existia o conjunto de cantores que homenageava Dionísio, participando de rituais e danças, que posteriormente seriam levados para a tragédia e para o teatro. Com características de ser um corpo uníssono, que, na Grécia, trazia informações, "antecipava, comunicava, previa, refletia as ações do herói e do desenvolvimento da tragédia" (Koudela; Almeida Junior, 2015, p. 33), ao largo do tempo, o papel do coro foi perdendo espaço na dramaturgia e foi ressurgindo como uma noção vinculada à encenação contemporânea Sarrazac (2002), que é a noção de coralidade.

Coralidade seria uma disposição especial de vozes que não substituiu nem o diálogo, nem o monólogo, mas que permite apontar uma maneira que varia segundo cada autor, de preencher as lacunas do dialogo. Nesse sentido, a coralidade é o inverso do coro, pois postula a discordância. [ss] (Koudela; Almeida Junior, 2015, p. 33, grifo das autoras).

O Coro dos Maus Alunos é uma obra dramatúrgica que não se refere ao "mau aluno" segundo Pennac, nem ao sentido de "coro" segundo os primórdios do teatro. O texto de Tiago Rodrigues trata da relação de sete alunos com um professor de filosofia, libertário e pouco convencional, que encanta um grupo de alunos e faz com que as relações sejam tensionadas entre professores, alunos, diretores e familiares. Um inquérito é aberto na escola, levando a uma situação extrema que leva esses alunos a serem definidos como o "coro dos maus alunos".

\#barbara: mesmo não se referindo às acepções mais clássicas do coro, as práticas de treinamento de atores e atrizes levaram em alta conta a coralidade como prática de existência em cena. Como diretoras, buscamos diluir a ideia de personagem, fundindo todos/as em uma figura maior que é o coro. Duas a três pessoas dividiam um mesmo personagem, sendo que diversas falas e situações já são indicadas no próprio texto, pelo autor, como coletivas. No prólogo do texto, por exemplo, os atores e atrizes não decoraram as falas dos personagens, mas sim, todo o texto, que eles entoam conjuntamente. Essa fala compartilhada criou uma estratégia de escuta de si e do outro para formar uma sonoridade difusa, que vai da confusão ao silêncio, na qual sobram vozes solitárias ou se alçam sonoros uníssonos que causam uma experiência auditiva diferenciada para o público e, com certeza, uma vivência mais aguçada do texto por parte de atores e atrizes em cena. A necessidade de estar permanentemente em contato com o todo, dividindo responsabilidades e atenções, cria outro tipo de conexão entre os atores e atrizes na cena. Pensando a ideia de discordância que a Heloise traz para a coralidade, a sonoridade vocal criada no trabalho é fundada na confusão e no choque, no desencontro, e não em uma organização formal que organiza as vozes coletivamente como, por exemplo, quando pensamos sonoramente no canto coral. Ao contrário disso, é contínuo embate de forças, é amor pelo caos. 
\#heloise: outro aspecto importante foi a opção que fizemos por valorizar os materiais escolares e lidar com eles. A sala de aula, as carteiras, o quadro, o giz, os cadernos, os lápis, os livros, os cartazes (cartolinas) são o que Masschelein e Simons (2014) chamam de "a tecnologia escolar". Essa tecnologia tem uma simplicidade, quase uma precariedade, que, justamente por isso, tem potencial para ser explorada poeticamente. São imediatamente reconhecidas, tendo em vista que quando olhamos uma sala de aula daqui e de um lugar no outro extremo do planeta, sabemos que se trata de uma sala de aula, justamente porque não há ambiguidade nesses materiais, e, com isso, podemos explorá-los poeticamente, criando sentidos vinculados ao signo imediatamente reconhecido e o significado transformado a partir do jogo teatral.

\#barbara: nesse sentido, o uso das carteiras escolares como objetos onipresentes, que influenciam os corpos dos atores e atrizes e mudam continuamente o desenho do espaço de cena, dialoga diretamente com essa "tecnologia escolar". Durante o processo, ao estudar sobre as ocupações dos secundaristas no Brasil em 2016, a estética dos empilhamentos de carteiras e cadeiras nos chamou a atenção. A subversão destes objetos que inicialmente eram "organizadores" do corpo do/a aluno/a nos interessou muito, tanto do ponto de vista visual, quanto do ponto de vista do treinamento corporal dos alunos e alunas.

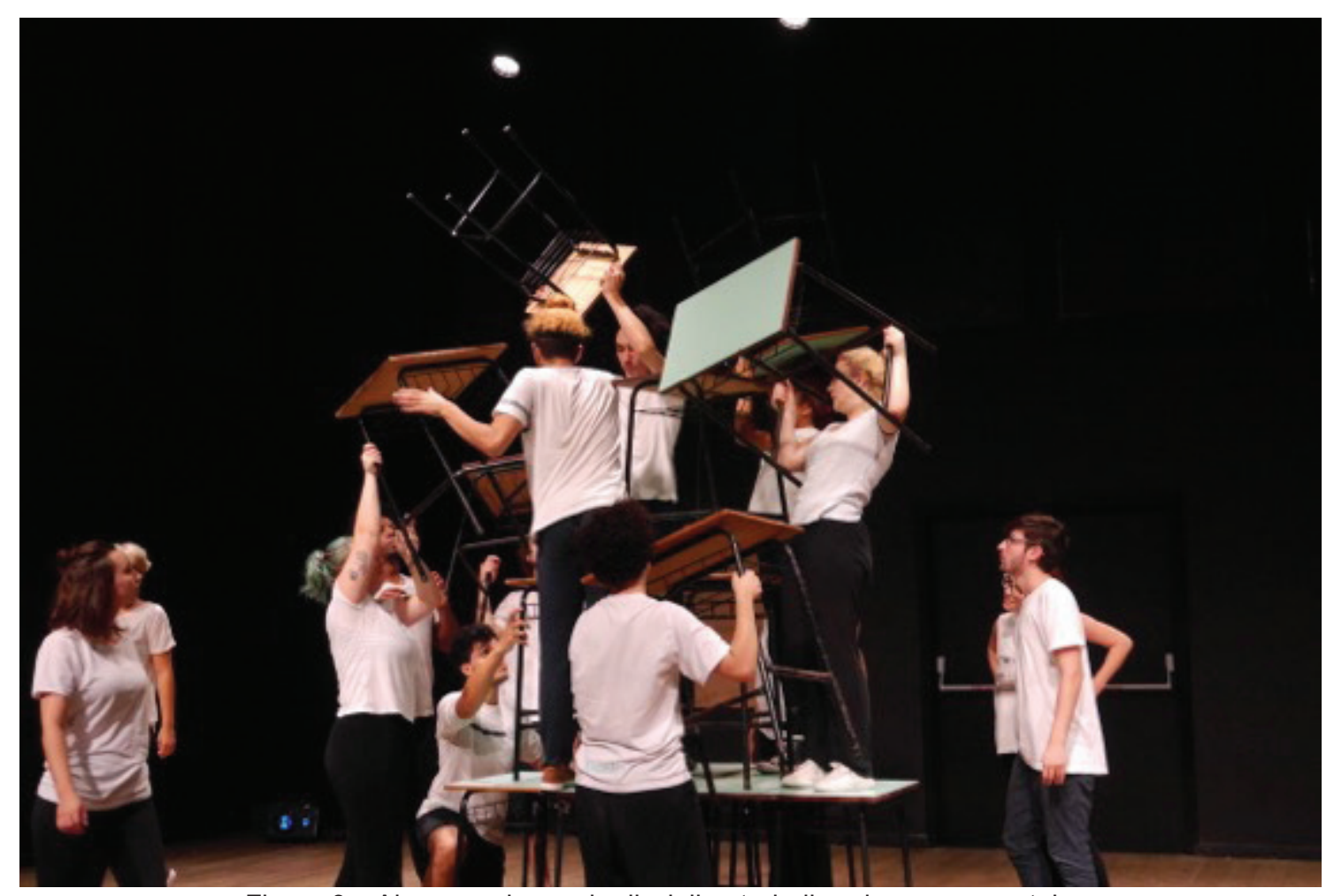

Figura 3 - Alunos e alunas da disciplina trabalhando com as carteiras. Arquivo da Montagem. Foto: Mariana Smania/ (2018).

\#heloise: assim, o espetáculo foi concebido a partir de três elementos fundamentais: o texto, feito na íntegra e sem substituições de palavras ou frases; a carteira escolar como único objeto cênico; a coralidade como aspecto de 
discordância no coletivo (Sarrazac, 2002). A coralidade presente na obra de Rodrigues nos remete a outro aspecto interessante postulado por Masschelein e Simons (2014), que é a ênfase na dimensão coletiva do aprendizado na escola. A escola não está para se ocupar de aprendizagem individual, para isso há outros meios mais eficazes. A dimensão do que é comum, na escola, é fundamental.

\#barbara: um dos retornos mais interessantes do público, no processo de apresentação do espetáculo, é a força do coletivo em cena. Ninguém se sobrepõe a ninguém, todos/as ganham e dão protagonismos em diferentes momentos. Essa conquista, para mim, não foi somente uma conquista técnica ou estética, baseada em uma forma pré-concebida de encenação. Ela é, na verdade, resultado de um amadurecimento interno do grupo, que aceitando as diferenças da coletividade pôde buscar as coisas que nos uniam em sala de trabalho. A entrega de todos/as os/ as envolvidos/as com a temática também revelou o quão apaixonante o universo da docência pode ser, e o quão urgente ele é. A tensão que permeia os alunos e alunas do curso de teatro na dicotomia entre "ser professor" e "ser artista" pôde ser discutida ao extremo, revelando suas falhas, suas dificuldades, suas belezas e seus paradoxos.

\#heloise: volto ao texto e me chama a atenção, desde a primeiríssima leitura: a possibilidade de olhar para a escola e olhar para os jovens que estão na escola.

\#barbara: e como sentimos, durante o processo, estar preenchendo uma lacuna de teatro voltado ao público jovem, tão difícil de encontrar nos dias atuais.

\#heloise: o estudo do livro Em defesa da escola: uma questão pública de Jan Masschelein e Maarten Simons (2014) desde 2016 encontrou com o texto de Rodrigues uma forma de dialogar através da cena. Fiquei muito sensibilizada pela ideia de que a escola é um lugar que oferece "tempo livre" para o estudo e transforma o conhecimento e as habilidades em "bens comuns", tendo assim o potencial para dar a todos, independente dos antecedentes, a oportunidade de mudar de forma imprevisível o mundo. Essa ideia de escola, defendida por Masschelein e Simons, é muito radical e vai de encontro às falas que priorizam o aprendizado voltado para uma finalidade, em última instância, a finalidade do mercado. A imprevisibilidade na forma de mudar o mundo é uma ideia potente, mas difícil de sustentar por quem está no dia a dia da sala de aula. E nos remetendo ao campo da Arte, isso nos faz entender porque a presença dela na escola é tão complicada, tensa, e ao mesmo tempo, muito desejada. 


\section{Referências}

KOUDELA, Ingrid D.; ALMEIDA JUNIOR, José S. de A. (Org.). Léxico da pedagogia do teatro. São Paulo: Perspectiva: SP Escola de Teatro, 2015.

LARROSA, Jorge. Esperando não se sabe o quê - Sobre o ofício de professor. Tradução: Cristina Antunes. Belo Horizonte: Autêntica, 2018.

MASSCHELEIN, Jan; SIMONS, Maarten. Em defesa da escola: uma questão pública. Tradução: Cristina Antunes. Belo Horizonte: Ed. Autêntica, 2014.

PENNAC, Daniel. Diário de Escola. Tradução: Leny Werneck. São Paulo. Rocco, 2008.

RODRIGUES, Tiago. Coro dos Maus Alunos. Texto não publicado, cedido pelo autor, 2008.

SARRAZAC, Jean-Pierre. (Org.). Léxico do drama moderno e contemporâneo. Tradução: André Telles. São Paulo: Cosac Naify, 2012.

Recebido em: 19/11/2018

Aprovado em: 05/02/2019 